\title{
Desafios da comercialização da piscicultura no município de Arari no Estado do
}

\section{Maranhão}

\author{
Challenges for the commercialization of fish farming in the municipality of Arari in the State of
}

\section{Maranhão}

Desafíos para la comercialización de la piscicultura en el municipio de Arari en el Estado de

\section{Maranhão}

\section{Resumo}

A piscicultura é uma atividade econômica que vem ganhando espaço e crescendo nos últimos anos, tornando-se alternativa de renda que contribui para alavancar a geração de emprego no meio rural. O município de Arari-MA se destaca no que diz respeito à atividade piscícola que representa uma das atividades potenciais da região. No entanto tem sido acompanhada de problemas que dificultam o desenvolvimento da atividade. Nesse sentido o objetivo do trabalho foi identificar os principais desafios encontrados na comercialização dos pescados para os produtores da associação dos piscicultores de Arari “ASPAR". A fase seguinte correspondeu as entrevistas através de questionários, onde 11 produtores da ASPAR participaram visando obter informações sobre a comercialização. Constatou-se que os principais entraves no processo de comercialização ocorrem devido ao custo elevado de insumos, obtenção de documentação, mão de obra, limitações na busca de canais de comercialização, falta de assistência técnica. A falta de documentações como o licenciamento ambiental impede a obtenção de créditos junto aos bancos, comprometendo a comercialização principalmente no que diz respeito à compra da ração, e na construção de estruturas para a venda direta do pescado ao consumidor final, refletindo na baixa lucratividade. Recomenda-se que os piscicultores da ASPAR busquem uma maior organização dentro da associação para neutralizar principalmente o problema referente à compra da ração, exigindo também de instituições públicas e privadas ações estratégicas no sentido de melhorar o processo de comercialização principalmente em relação a legalização e assistência técnica para as pisciculturas.

Palavras-chave: Produção de peixes; Venda; Fatores limitantes. 


\begin{abstract}
Fish farming is an economic activity that has been gaining ground and growing in recent years, becoming an alternative income that contributes to leveraging the generation of employment in rural areas. The municipality of Arari-MA stands out with regard to the fish activity that represents one of the potential activities in the region. However, it has been accompanied by problems that hinder the development of the activity. In this sense, the objective of the work was to identify the main challenges found in the commercialization of fish for the producers of the association of fish farmers of Arari "ASPAR". The next phase corresponded to the interviews through questionnaires, in which 11 ASPAR producers participated in order to obtain information on the commercialization. It was found that the main obstacles in the commercialization process occur due to the high cost of inputs, obtaining documentation, labor, limitations in the search for commercialization channels, lack of technical assistance. The lack of documentation such as environmental licensing prevents obtaining credits from banks, compromising commercialization mainly with regard to the purchase of feed, and in the construction of structures for the direct sale of fish to the final consumer, reflecting on low profitability. It is recommended that ASPAR fish farmers seek a greater organization within the association to neutralize mainly the problem related to the purchase of feed, also requiring public and private institutions to take strategic actions to improve the marketing process, especially in relation to legalization and assistance. technique for fish farms.
\end{abstract}

Keywords: Fish production; Sale; Limiting factors.

\title{
Resumen
}

La piscicultura es una actividad económica que ha ido ganando terreno y creciendo en los últimos años, convirtiéndose en una alternativa de ingresos que contribuye a apalancar la generación de empleo en el medio rural. El municipio de Arari-MA se destaca en cuanto a la actividad pesquera que representa una de las actividades potenciales en la región. Sin embargo, ha ido acompañado de problemas que dificultan el desarrollo de la actividad. En este sentido, el objetivo del trabajo fue identificar los principales desafíos encontrados en la comercialización de pescado para los productores de la asociación de piscicultores de Arari "ASPAR". La siguiente fase correspondió a las entrevistas a través de cuestionarios, en las que participaron 11 productores de ASPAR con el fin de obtener información sobre la comercialización. Se encontró que los principales obstáculos en el proceso de comercialización se dan por el alto costo de los insumos, obtención de documentación, mano de obra, limitaciones en la búsqueda de canales de comercialización, falta de asistencia técnica. La falta de documentación como la licencia ambiental impide la obtención de créditos bancarios, comprometiendo la comercialización principalmente en lo que se refiere a la compra de piensos, y en la construcción de estructuras para la venta directa de pescado al consumidor final, reflejando una baja rentabilidad. Se recomienda que los piscicultores de ASPAR busquen una mayor organización dentro de la asociación para neutralizar principalmente el problema relacionado con la compra de piensos, requiriendo también que las instituciones públicas y privadas tomen acciones estratégicas para mejorar el proceso de comercialización, especialmente en lo que se refiere a la legalización y asistencia técnica para piscifactorías.

Palabras clave: Producción pesquera; Venta; Factores limitantes.

\section{Introdução}

A piscicultura tem garantido espaço nas discussões, como alternativa de renda para o meio rural, e em políticas governamentais específicas. Tal fato se deve ao crescimento substancial da atividade e às características propícias que cada região possui para esta área e que leva a acreditar que a criação de peixes possa dar importante contribuição para alavancar a geração de emprego e renda para o setor rural (Vidal, 2016).

A pesca no Brasil apresenta importância social, tanto no contexto local, como regional, sendo fonte de subsistência de populações ribeirinhas que dependem desta atividade diretamente ou indiretamente através de atividades relacionadas (SANTOS et al., 2012). Os principais problemas para o desenvolvimento da piscicultura no Nordeste, especificamente no Maranhão, são a insuficiência ou falta de assistência técnica, canais inadequados e comercialização, desinteresse das unidades de beneficiamento para os pequenos e médios produtores, condições climáticas adversas e dificuldade de obtenção de licenciamento ambiental que por sua vez impede o acesso ao crédito (Vidal, 2016).

Diversos estudos, sobretudo no Norte e Nordeste, têm buscado caracterizar a piscicultura para o desenvolvimento da atividade (Araújo; Sá, 2008; Carvalho; Souza; Cintra, 2013; Estevão-Rodrigues; Estevão-Rodrigues, 2017; Nakauth, 2015). Conhecer as limitações da atividade e suas características locais possibilita o desenvolvimento de políticas para alavancar a produção, fornecendo subsídios de incentivo à agricultura familiar, fundamental ao desenvolvimento rural pela contribuição para geração de emprego e renda e, por conseguinte, segurança alimentar (Elias et al., 2019). 
A forma como funciona o canal de distribuição é o que determina o preço final para o consumidor, a consolidação dos supermercados como um dos principais canais de venda de peixe no Brasil tem sido um elemento chave para sua popularização no mercado doméstico. Na região Nordeste, como na Baixada Maranhense, a comercialização do peixe acontece, principalmente, em feiras livres e mercados municipais (Silva, 2016). No município do Maranhão, Arari, os principais meios de comercialização são através dos produtores diretos e os produtores intermediários, vendem para feirantes ou restaurante e vendem na feira, respectivamente.

Devido a importância socioeconômica da piscicultura no município de Arari e as fragilidades que essa atividade vem passando no processo de comercialização este trabalho tem como objetivo identificar os principais desafios encontrados na comercialização dos produtores da associação dos piscicultores de Arari “ASPAR"

\section{Material e Métodos}

A pesquisa foi realizada no município de Arari no estado do Maranhão, devido a sua importância na produção de pescados na região. O município localiza-se no sul do equador, e como coordenadas geográficas em seus extremos temos: ao

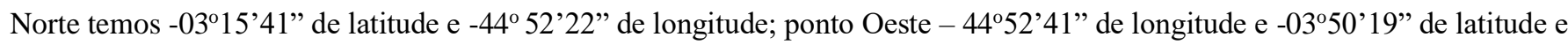
$-44^{\circ} 36^{\prime} 34^{\prime \prime}$ de longitude; ponto Leste $-44^{\circ} 35^{\prime} 37^{\prime \prime}$ de longitude e $-03^{\circ} 26^{\prime} 43^{\prime \prime}$ de latitude. A sede municipal vem ser localizada a $3^{\circ} 27^{\prime} 00^{\prime \prime}$ de latitude sul e 444' $48^{\prime \prime}$ de longitude. Arari situa-se a leste da capital, integrando a região da baixada maranhense e fazendo parte da região norte Maranhense (Figura 1). A área do município é de 1.100,3 $\mathrm{km}^{2}$ representando 0,33\% de todo o território do Maranhão (Bani, 2016).

Figura 1. Mapa de localização do município de Arari - MA

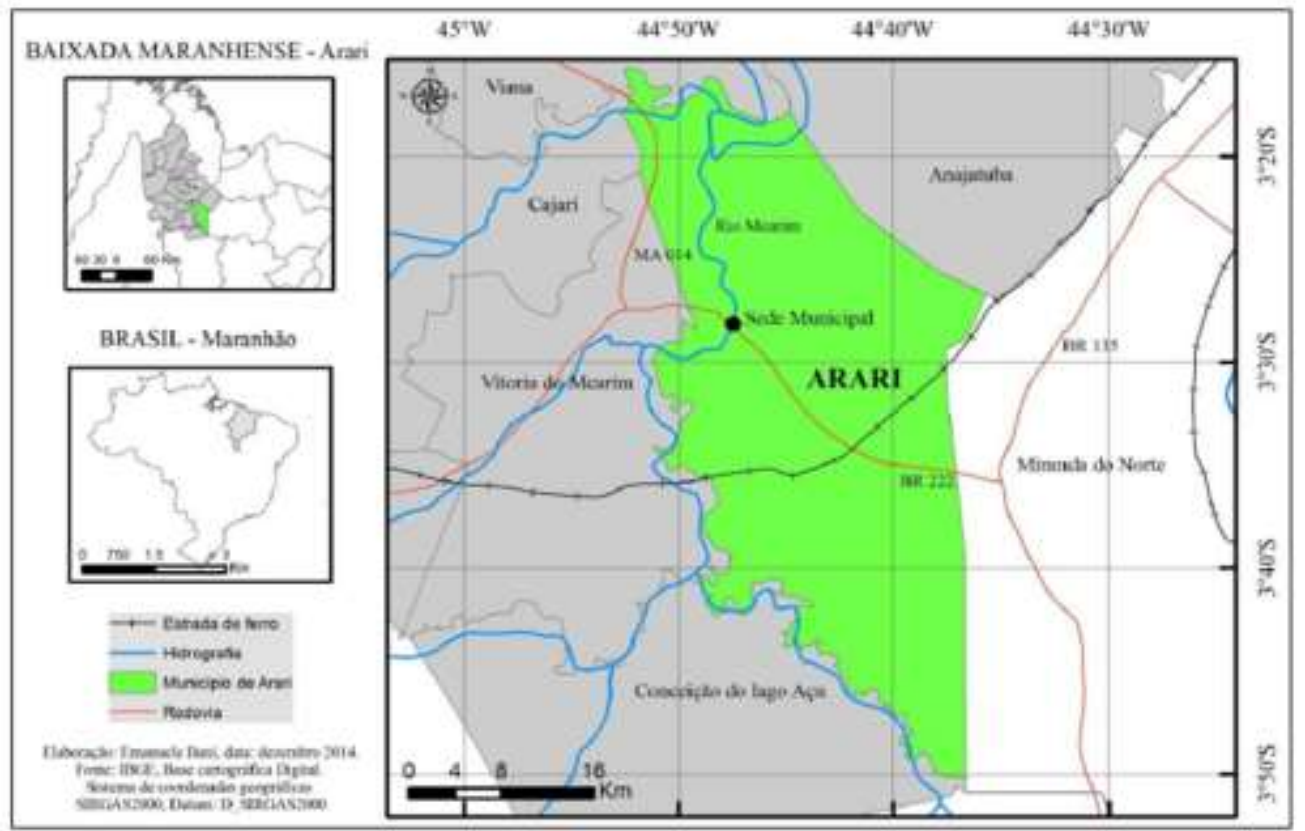

Fonte: Bani (2016).

A região da baixada maranhense é rica em recursos pesqueiros, onde a atividade é uma das mais marcantes, levando-se em consideração a socio economia regional. A principal Bacia Hidrográfica da região da Baixada é o Rio Mearim, é um dos principais rios do Maranhão, utilizado como local que provê importantes recursos pesqueiros para várias comunidades de muitos municípios maranhenses. Desta forma o município de Arari e toda a microrregião da baixada maranhense se destaca no que diz respeito à pesca, por ser uma atividade que representa uma importante fonte de alimento e renda, entretanto a pesca artesanal 
vem sendo substituída pela produção em cativeiro ou piscicultura que vem se destacando nos últimos anos. No município de Arari os produtores utilizam de dois a três hectares de lâmina de água para a criação de diversas espécies, como: Tambacu (Colossoma Macropomum x Piaractus Mesopactamicus); Tambatinga (Colossoma Macropomum x Piaractus brachypomum); curimatã e curimbatá (Prochilodus lineatus); Tambaqui (Colossoma Macropomum); Pacu (Piaractus mesopotamicus); patinga (Piaractus brachypomus) e Tilápia (Oreochromis niloticus) (Machado, 2016; Bani, 2016).

Esse trabalho foi direcionado aos produtores de pescado da associação dos piscicultores de Arari “ASPAR" e para os demais produtores presentes na região. foi feito a aplicação do questionário elaborado por autoria própria. Nesta etapa da pesquisa foram realizadas entrevistas, com cada produtor de pescados da ASPAR, por meio de ligações celular/celular para assegurar a saúde dos entrevistados devido à pandemia do COVID-19. Os contatos dos entrevistados irão ser obtido diretamente com o líder da associação. Esse método de aplicação de questionários é escolhido devido à praticidade e porquê boa parte dos entrevistados possuem celulares e conhecimento sobre o uso de ferramentas de comunicação. Durante a entrevista os principais questionamentos que tratou-se saber foram: Quais as espécies de peixes produzidos; para quem é vendido o pescado e se o valor da venda compensa o trabalho, tratou-se saber também as principais dificuldades encontradas na produção do pescado, como: preço da ração, mão de obra, documentação e em que sentido a associação dos piscicultores de Arari participa do processo de produção.

O questionário foi construído de tal modo que possibilitasse coletar informações como o nível de bem estar social e a percepção econômica dos produtores em relação ao objetivo do estudo, no caso os desafios da comercialização de pescado. É importante salientar que, a pesquisa qualitativa é importante porque tende a colocar questões utilizando "o quê", "como" e "porquê", e a analisar as respostas no contexto da vida quotidiana e dos significados e explicações atribuídos por cada indivíduo em relação ao tema estudado. Quando realizada corretamente, oferece um caminho metodológico para a compreensão, em profundidade, de padrões, incluindo os padrões da economia, e como esses padrões podem influenciar e interagir para a identificação de prioridades e necessidades relevantes nos contextos sociais, culturais e econômicos específicos e/ou grupos de indivíduos, e assim implementar intervenções apropriadas (Campos; Siqueira, 2018). Portanto a tipologia da pesquisa é considerada um estudo exploratório e descritivo, pois tem como característica esclarecer os limites e as possibilidades do desenvolvimento da atividade piscícola no munícipio de Arari-MA

De posse das informações, foi possível organizar os dados coletados com a elaboração de gráficos, tendo como recurso o programa da Microsoft Excel 2016. Dessa forma, foi possível responder nosso objetivo de trabalho que foi identificar os principais canais de comercialização e desafios encontrados na comercialização de pescados no município de Arari-MA.

\section{Resultados e Discussão}

Dos 11 piscicultores que foram entrevistados, todos citaram a Tambatinda (Colossoma Macropomum x Piaractus brachypomum) como produzida em sua propriedade, seguido de Curimatá $=7$, Capadinho $=3$, Pirarucu $=1$ e Pacu manteiga $=1$ (Figura 2). Resultado semelhante foi encontrado por Lopes al., (2020) que também constataram que a Tambatinga também era a espécie de maio interesse pelos piscicultores com 44\% seguida da Tilápia com 35\% em Araioses/MA (Meante; Dória, 2018) relataram que o Tambaqui era a espécie mais cultivada pelos piscicultores do estado de Rondônia com 72\%, a curimatá também aparecia com uma das espécies mais cultivadas. Segundo os piscicultores da região "a Tambatinga e a Curimatá são os peixes que são mais vendidos na região, sendo eles os mais procurados por atravessadores e intermediários o que facilita o processo de venda desses peixes em grandes quantidades". 
Figura 2. Peixes mais produzidos pelos piscicultores de Arari-MA.

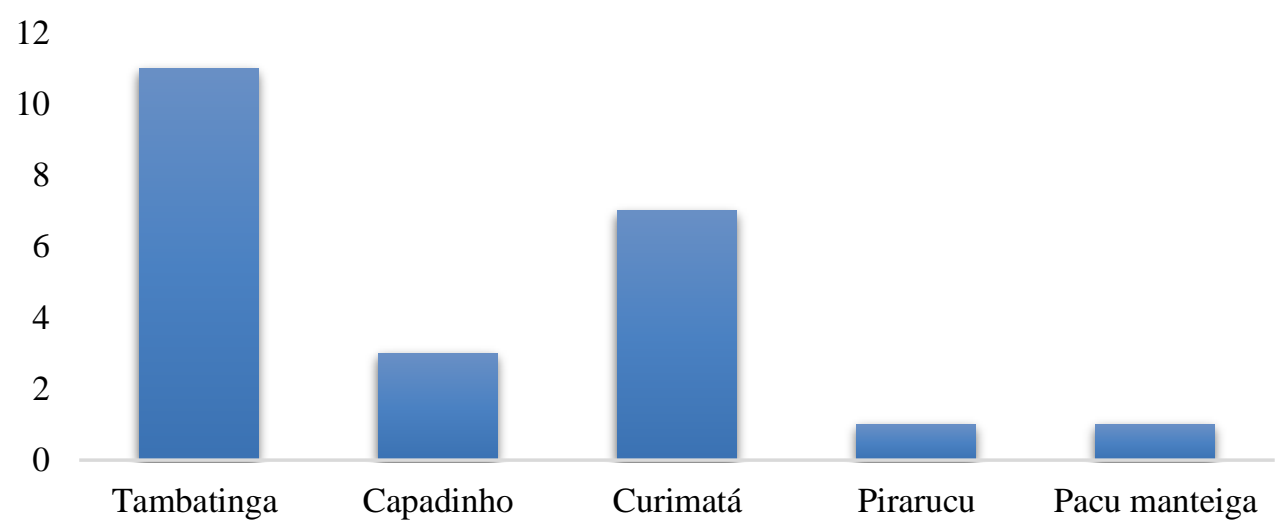

Fonte: Autores.

Em relação a venda do pescado a maioria dos piscicultores entrevistados 63,60 \% relataram que não consideram o preço de venda injusto, 36,36 \% consideram o preço de venda justo. Resultado semelhante foi encontrado por (Meante; Dória, 2018), que encontraram uma parcela de 10 de 34 piscicultores com resposta que consideravam os preços de venda baixo do pescado. Segundo os piscicultores entrevistados no trabalho "não é justo devido aos altos valores cobrados pelos insumos, principalmente a ração, sendo um dos fatores mais determinante para baixa lucratividade na atividade". O baixo investimento feito pelos piscicultores, falta de tecnologias para implantar nas áreas de produção e mais opções de venda do pescado também foram citadas como os um dos fatores que tornam essa atividade produtiva frustrante e pouco compensatória. Como alternativa para aumentar o lucro na produção do pescado (Meante; Dória, 2018) observaram que alguns dos piscicultores entrevistados em seu trabalho possuem o próprio material para a realizar a despesca e transporte, além de comercializar sua produção em veículos próprios, vendendo em suas propriedades ou em locais próximos ao empreendimento piscícola (Meante; Dória, 2018). Essa atividade de venda diretamente do produtor para o consumidor final também poderia ser adotada pelos piscicultores ASPAR de maneira organizada e em conjunto com o apoio da prefeitura do município de Arari, fortalecendo assim a piscicultura na região do município, gerando um maior valor agregado na venda do peixe.

Figura 3. Você considera o preço de venda do peixe justo?

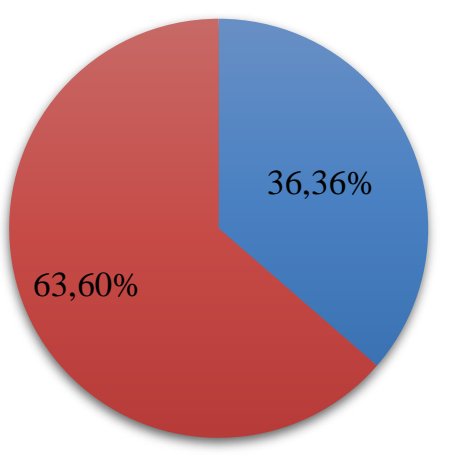

- Sim não

Fonte: Autores. 
Com relação aos canis de comercialização temos que todos os 11 piscicultores entrevistados escoam sua produção por meio de atravessadores, esse canal na região é representado por caixeiros de outras regiões que vem buscar em Arari o pescado para revender para restaurantes e peixarias etc. O canal de comercialização através de intermediários se apresentou como sendo o segundo maior canal observado, citado por 4 piscicultores, este é representado na região por pequenos compradores que vendem o peixe diretamente na feira de Arari (Figura 4). Em menor quantidade foi citado por 2 piscicultores o canal de comercialização diretamente para o consumidor final. Em seu trabalho (Barros et al., 2018) observaram que 44,4\% da comercialização do pescado era feita para o frigorífico e o canal de comercialização direto para o consumidor final representou $25 \%$. O piscicultor deve buscar o canal que gere o maior valor de comercialização, melhor preço de venda chegando diretamente no consumidor, agregando valor ao produto em função dos diferentes nichos de mercado, o que permite melhorar a receita da atividade (Barros et al., 2018).

Figura 4. Para quem você vende o pescado?

\section{2 \\ 10 \\ 8 \\ 6 \\ 4 \\ 2 \\ 0}

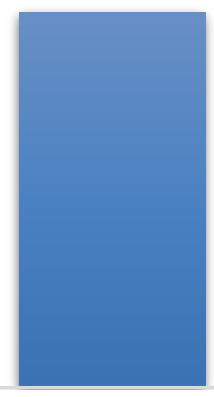

Atravessadores

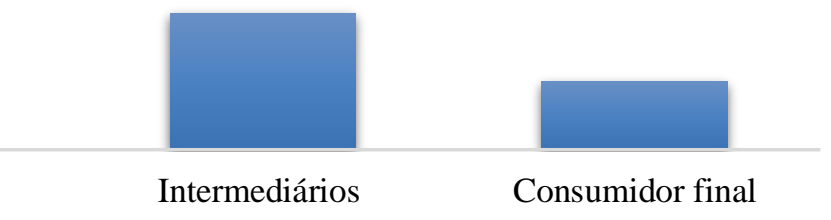

Fonte: Autores.

A maioria dos piscicultores entrevistados relataram que não consideram o valor de venda dos peixes justo, sendo representado por 72,72\%, somente 27,27\% consideram o valor de venda justo (Figura 5). Segundo os piscicultores entrevistados "o valor da venda do Kg produzido de pescado não é justo devido ao aumento anual dos custos de produção, principalmente referente a ração que é fornecida para os peixes". De acordo com Vidal (2016) e Zacardi et al., (2017) um dos principais problemas enfrentados pelos produtores é o preço da ração que é o mais importante dos custos operacionais da atividade, sendo assim um dos principais entraves para o desenvolvimento da psicultura, isto ocorre porque o preço da ração e das matérias primas para a produção, como o milho e a soja estão muito relacionados e são demandados em grande quantidade nas rações.

Em algumas regiões do Nordeste, a atividade agrícola se torna uma atividade secundaria de subsistência (De Oliveira; Florentino, 2018). Com base nessa premissa a obtenção da ração comercial pode diminuir se for realizado pesquisas adequadas de tal forma que aproveite todo o potencial de insumos da região, uma vez que haverá integração entre as atividades agrícolas, auxiliando no aumento da produtividade das criações e, consequentemente, na manutenção da atividade. Assim, o uso de boas práticas de manejo alimentar pode contribuir com a otimização da produção (Zacardi, 2017).

Outra alternativa que os piscicultores da ASPAR poderiam buscar, seria tentar agregar valor no seu produto com beneficiamento e a vender dos cortes dos peixes comercializados. Em seu trabalho Pedroza Filho et al. (2014) destacou que no Brasil vem aumentando a demanda por produtos derivados do pescado que sejam mais práticos para o consumo como filé, peixe defumado, espetinho de peixe e costelinha. Um dos fatores que limitariam essa ação sendo mencionado por alguns dos piscicultores entrevistados é a falta de estrutura, que também impede a venda do pescado direto para o consumidor final. 
Figura 5. O valor que você vende o pescado é justo e compensa seu trabalho?

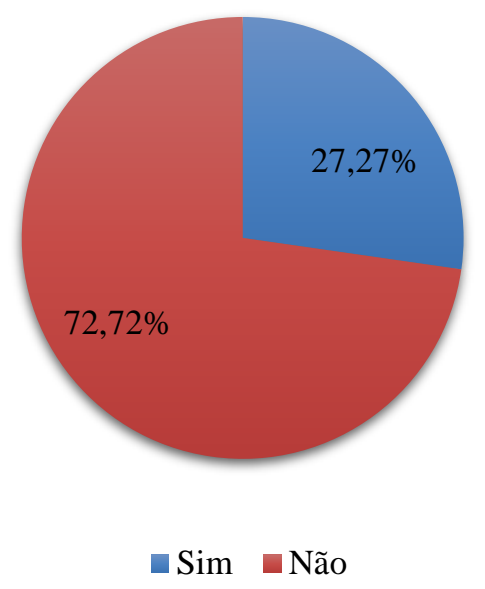

Fonte: Autores;

A maioria dos piscicultores entrevistados 63,63\% tem intenção de vender o seu pescado diretamente para o consumidor final, enquanto que 36,36\% não tem a intenção de vender diretamente ao consumidor final (Figura 6). Em seu estudo Barros et al., (2018) de caracterização das pisciculturas localizadas na microrregião da Baixada Cuiabana-MT, por meio de entrevistas junto aos piscicultores, verificou-se que a comercialização direta com o consumidor, o preço do quilograma do peixe variou de $\mathrm{R} \$ 4,00$ a $\mathrm{R} \$ 14,00$, dependendo da espécie, outros autores também destacaram que o preço inicial do quilograma da tilápia para frigoríficos era de 2,40 $\mathrm{R} \$$ porem duplicou o seu valor quando comercializado diretamente com o consumidor final e triplicou quando comercializado no varejo. Portanto o pescado chegando diretamente ao consumidor é importante para se obter um melhor preço de venda agregando um maior valor ao produto em função dos diferentes nichos de mercado.

Figura 6. Você tem a intenção de vender seus produtos diretamente ao consumidor final?

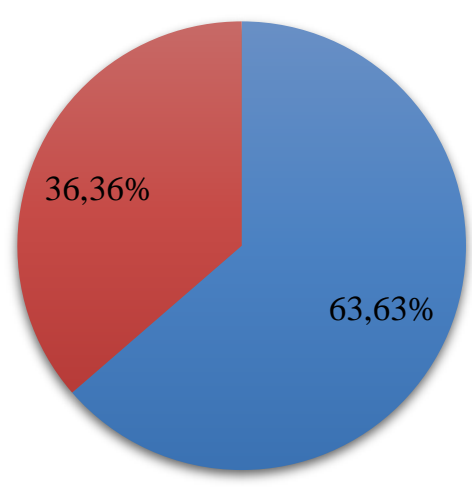

\section{• Sim $\square$ Não}

Fonte: Autores.

Foi constatado que as principais dificuldades dos produtores são a compra de insumos relatada por 5 piscicultores, mão de obra $=5$ e na obtenção de documentação $=3$ (Figura 7). Em seguida também foram relatados conhecimentos de manejo =2, acesso a água $=2$, venda de peixes $=1$, equipamentos $=1$ e empréstimos bancários 1 . Segundo alguns piscicultores entrevistados no tralho "os valores cobrados pelo preço da ração aumentam a cada ano o que eleva muito o custo de produção do pescado, em 
contrapartida o preço de venda do pescado não aumenta, deixando assim a atividade menos lucrativa". Também foi constatado que a compra de insumos principalmente a ração representou a principal limitação para o desenvolvimento da piscicultura na região de Rondônia. $\mathrm{O}$ alto preço cobrado pela ração ocorre devido ao aumento do preço das principais matérias primas que são a soja e milho. A ração chega a representa certa de $70 \%$ do custo de produção para produzir o pescado, esse desequilíbrio entre o preço da ração e o do peixe inviabilizam o desenvolvimento da piscicultura na região (Meante; Dória, 2018).

A mão de obra não foi considerada uma dificuldade no trabalho de Martins et al. (2018) uma vez que os piscicultores entrevistados no seu trabalho utilizavam mão-de-obra familiar, por isso esses produtores não tinham altos custos trabalhistas, porem essa é pouco qualificada e não a investimento na sua capacitação. Segundo os piscicultores de Arari "temos dificuldade em contratar funcionários na região para fazer as atividades de manejo da área como limpeza dos tanques ou capina, alimentação dos peixes e na parte final que se resume a retirada dos peixes para venda".

$\mathrm{Na}$ legalização das propriedades pode-se observar uma grande dificuldade por parte dos piscicultores em obter determinadas documentações como licenciamento ambiental. Dificuldade semelhante na piscicultura foi relatada no trabalho de (Pedroza Filho et al., 2014; Barros et al., 2018). O licenciamento ambiental é um dos principais gargalos da piscicultura. A ausência dessa documentação impede o produtor de ter acesso às linhas de crédito dos bancos além de prejudicar o processo de produção do pescado (Filho et al., 2014). Esse problema se relaciona diretamente ao fato de alguns produtores entrevistados relatarem a falta de capital para o investimento na produção uma vez que eles não conseguem obter esses empréstimos bancários.

Figura 7. Quais são as principais dificuldades encontradas na produção do pescado?

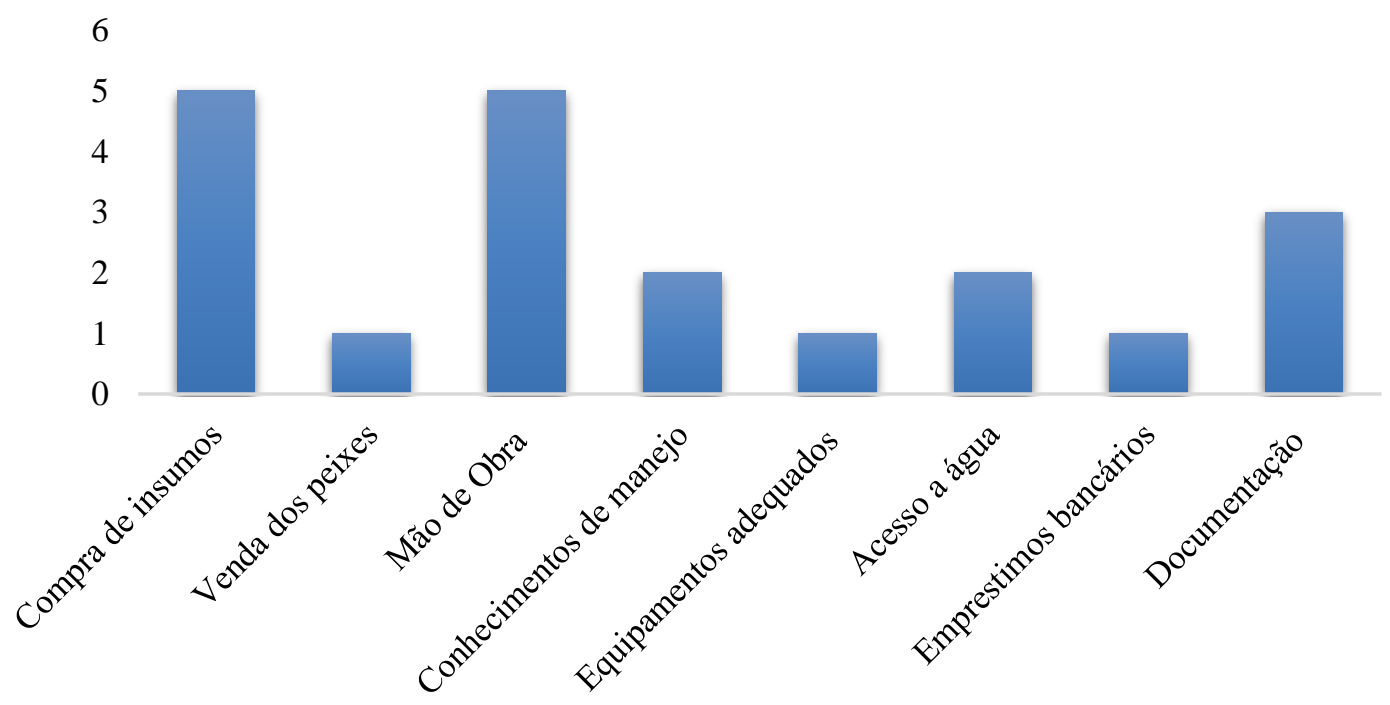

Fonte: Autores.

A ASPAR tem como principais atividades desempenhadas no processo produtivo a compra de insumos, sendo citado por 10 piscicultores e obtenção de documentação $=5$, as demais ações desempenhadas pela associação são transporte da ração $=2$, infraestrutura das estradas, repasse de compradores $=1 \mathrm{e}$ assistência técnica= 1 (Figura 8). Em seu trabalho (Barros et al., 2018) mostra que 100\% da Associação dos Aquicultores do Mato Grosso (Aquamat) citam a representação da associação principalmente na formulação da lei estadual específica para piscicultura como maior ação, seguida de parcerias com o Serviço de Apoio às Micro e Pequenas Empresas (SEBRAE) e criação de grupo para compra de ração. A organização dos piscicultores 
em cooperativas e associações permite aos produtores vantagens como acesso ao melhor preço de insumos como calcário, adubo e rações pois, pela sua aquisição em grande quantidade (Meante; Dória, 2018).

Com relação a obtenção de documentação como a licença ambiental e a outorga de água foi relatado pelos piscicultores que a associação ajudou ou vem ajudando na obtenção desses documentos, sendo citada por 5 piscicultores (Figura 8). No contexto dessa legalização das propriedades algumas dificuldades também foram apontadas no trabalho de Barros et al., (2018) onde os piscicultores entrevistados citaram a falta de instruções claras para licenciamento e organização dos órgãos responsáveis $(45,8 \%)$, excesso de burocracia $(16,6 \%)$, bem como fiscalização mais eficiente $(42,9 \%)$. Durante a entrevista alguns piscicultores relataram que "existe muitas dificuldades em obter documentos referentes a legalização da propriedade por causa do excesso de burocracias", isso acaba desanimando os responsáveis da propriedade e por ocasião dessa dificuldade na legalização da propriedade muitos dos produtores não tem acesso a empréstimos bancários o que limita o crescimento da atividade (Filho et al., 2014). Com relação aos aspectos ambientais, a regularização dos projetos de piscicultura ajuda a desenvolver a atividade, ajustando a viabilidade econômica com a sustentabilidade ambiental. Infelizmente o processo de legalização não é eficiente (Barros et al., 2018).

Figura 8. A associação dos piscicultores de Arari “ASPAR” participa do processo de produção em qual sentido?

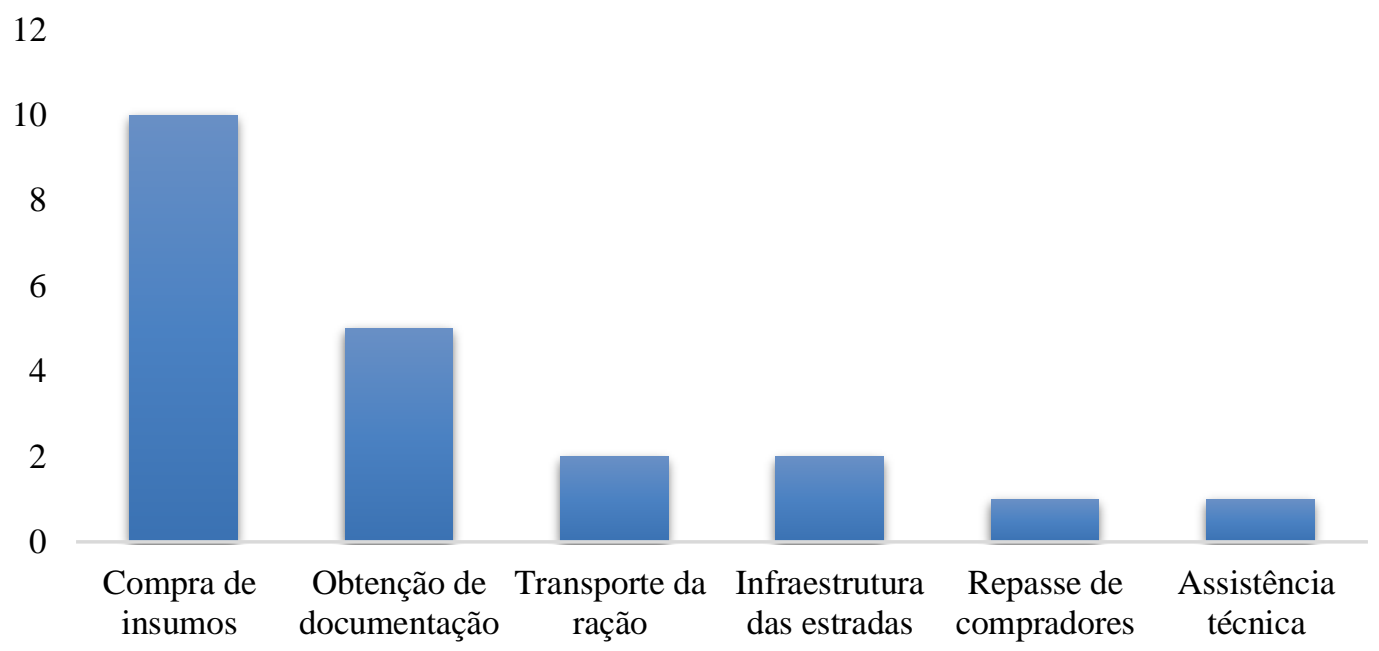

Fonte: Autores.

Mais da metade dos piscicultores entrevistados 63,63\% não recebem nenhuma assistência técnica na produção do pescado, enquanto que a minoria 36,36\% recebem alguma assistência técnica (Figura 9). Resultado diferente foi encontra no trabalho de (Barros et al., 2018) onde 87,5\% dos produtores tiveram acompanhamento técnico no projeto de implantação, porem os projetos de piscicultura não foram bem planejados mostrando assim a deficiência em profissionais qualificados na área. Segundo os piscicultores entrevistados "O SEBRAE fornecia assistência técnica para todos os piscicultores da associação, mas no ano atual nós deixamos de ter esse acompanhamento na produção" um produtor relatou que "Queremos que o município forneça assistência técnica na produção do pescado. As nossas limitações no manejo de produção seriam sanadas com o apoio de uma assistência técnica". A produção de organismos aquáticos engloba o suporte técnico, a conjuntura econômica e legal e a infraestrutura necessária para a produção. $\mathrm{O}$ fato da maioria dos piscicultores não receberem assistência técnica na produção do pescado pode interferir o rendimento da produção. Esse suporte técnico é fundamental para aplicação de conhecimentos de manejo no cultivo de peixes que envolvem o controle na qualidade de água, manejo nutricional, biologia da espécie a ser cultivada, tecnologia da produção de sementes entre outras (Meante; Dória, 2018). 
Figura 9. Você recebe alguma assistência técnica na produção do pescado?

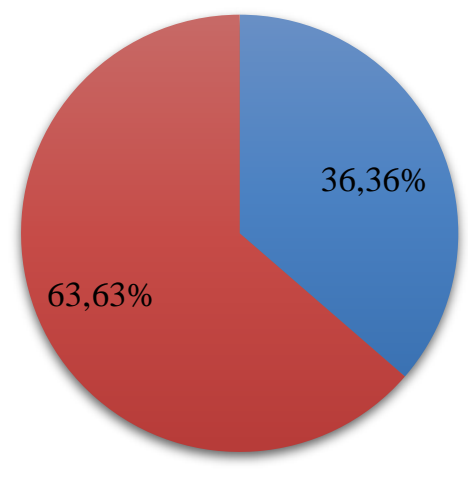

•Sim $\square$ Não

Fonte: Autores.

Todos os piscicultores entrevistados no trabalho $100 \%$ fariam algum curso de capacitação da piscicultura se fosse disponibilizado (Figura 10). Segundo alguns entrevistados "nós sabemos que é possível melhorar nosso manejo nessa atividade, hoje várias tecnologias são criadas para o desenvolvimento da piscicultura e nós não podemos deixa de acompanhar essa evolução". O baixo nível tecnológico principalmente dos pequenos piscicultores está relacionado a dificuldades no acesso de informações e em obter recursos. O reflexo desse problema reflete diretamente na baixa produtividade e nos elevados custos na produção do pescado que são provocados por sérios problemas (Pedroza Filho et al., 2014).

Figura 10. Você faria algum curso de capacitação na piscicultura?

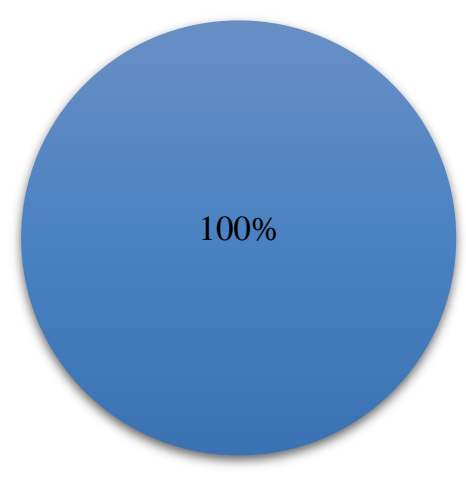

$$
\text { - Sim não }
$$

Fonte: Autores.

Os principais desafios encontrados pelos piscicultores da ASPAR no processo de comercialização do pescado foram a compra de insumos, principalmente a ração utilizada na alimentação dos peixes, obtenção de documentação e a mão de obra. Também foi possível observar implicitamente uma grande dificuldade destes produtores em comercializar o pescado em canais de comercialização mais lucrativos.

A falta de investimentos por parte dos piscicultores na produção do pescado está relacionada a falta de documentações como o licenciamento ambiental que impede a obtenção de créditos junto aos bancos, comprometendo a comercialização do 
pescado principalmente no diz respeito a compra da ração para os peixes e na construção de estruturas para venda direta do pescado ao consumidor final.

A abaixa lucratividade mencionado pelos produtores é relacionada principalmente aos custos referentes a compra de insumos principalmente a ração, falta de investimentos em infraestruturas de vendas, busca de canais de comercialização mais lucrativos e falta de assistência técnica que limita a entrada de novos conhecimentos de manejo que podem estar ligados ao baixo desempenho da produção.

\section{Conclusão}

A partir dos resultados encontrados nesse trabalho recomenda-se que os piscicultores da ASPAR busquem uma maior organização dentro da associação para neutralizar principalmente o problema referente à compra da ração, exigindo também de instituições públicas e privadas ações estratégicas no sentido de melhorar ações no processo de comercialização do pescado principalmente em relação a legalização e assistência técnica para as pisciculturas.

De maneira que, novos trabalhos devem ser realizados buscando abranger uma maior quantidade de piscicultores no município de Arari e abordar mais questões referentes ao processo de comercialização para a determinação dos principais entraves no desenvolvimento dessa atividade. Também é importante que novos estudos avaliem a sustentabilidade da atividade e os possíveis impactos ambientais gerados pela intensificação da produção, além de estudos referentes aos recursos hídricos, levando em consideração as bacias hidrográficas do estado para a realização de um zoneamento aquícola.

\section{Referências}

Araújo, J. S., \& Sá, M. F. P. (2008) Sustentabilidade da piscicultura no baixo São Francisco alagoano: condicionantes socioeconômicos. Revista Ambiente \& Sociedade, 11(2), 405-424.

Bani, E. et al. Segurança alimentar urbana na Baixada Maranhense: o caso do município de Arari. 2016.

Barros, A. F., Martins, M. I. E. G., \&Souza, O. M. (2018) Caracterização da piscicultura na microrregião da baixada cuiabana, Mato Grosso, Brasil. Boletim do Instituto de Pesca, 37(3), 261-273.

Campos, C. J. G., \&Siqueira, C. (2018) Investigação qualitativa: perspetiva geral e importância para as ciências da nutrição. Acta Portuguesa de Nutrição, (14), 30-34.

Carvalho, H. R. L., Souza, R. A. L., \& Cintra, I. H. A aquicultura na microrregião do Guamá, Estado do Pará, Amazônia Oriental, Brasil. Revista de Ciências Agrárias Amazonian Journal of Agricultural and Environmental Sciences, Amazonas, 56(1), 1-6, 2013.

De Oliveira, N. I. S., \& Florentino, A. C. (2018) Avaliação socioeconômica dos piscicultores do município de Porto Grande, Amapá, Brasil. Ciência e Natura, 40, e 31 .

Elias, L. P. et al. Impactos socioeconômicos do Programa Nacional de Alimentação Escolar na agricultura familiar de Santa Catarina. Revista de Economia e Sociologia Rural, Brasília, 57(2), 215-233, 2019.

Estevão-Rodrigues, T. T.., \& Estevão-Rodrigues, T. D. Piscicultura familiar, assistência técnica e práticas de manejo colheita e pós colheita: estudo de caso da região metropolitana de Manaus - Amazonas, Brasil. Revista Observatorio de la Economía Caracterização da piscicultura familiar na região do baixo Parnaíba - Araioses/MA 58 Extensio: R. Eletr. de Extensão, 17(36), 41-60.

Gomes, P. M. A., Barbosa, J. G., Costa, E. R., S. \& Junior, I. G. (2012) Avaliações das condições higiênicas sanitárias das carnes comercializadas na feira livre do município de Catolé do Rocha-PB. Revista Verde de Agroecologia e Desenvolvimento Sustentável, 7(1), 225 - 232.

Lopes, J. M. et al. (2020) Caracterização da piscicultura familiar na região do baixo Parnaíba-Araioses/MA. Extensio: Revista Eletrônica de Extensão, 17(36), 41-60.

Machado, D. S. Fecundidade e tipo de desova de Prochilodus lineatus (Characiformes, Prochilodontidae na área de proteção ambiental da Baixada Maranhense) Brasil. 2016. Tese de Doutorado. UEMA.

Martins, C. V. B. et al. (2018) Avaliação da piscicultura na região oeste do estado do Paraná. Boletim do Instituto de Pesca, 27(1), 77-84.

Meante, R. E. X., \& Da Costa Dória, C. R. (2018) Caracterização da cadeia produtiva da piscicultura no estado de Rondônia: desenvolvimento e fatores limitantes. Revista de Administração e Negócios da Amazônia, 9(4), 164-181,

Nakauth, A. C. S. S., Nakauth, R. F., \& Nóvoa, N. A. C. B. Caracterização da piscicultura no município de Tabatinga-AM. Revista Igapó-Revista de Educação Ciência e Tecnologia do IFAM, 9(2), 54-64, 
Research, Society and Development, v. 10, n. 4, e38710414371, 2021

(CC BY 4.0) | ISSN 2525-3409 | DOI: http://dx.doi.org/10.33448/rsd-v10i4.14371

Pedroza Filho, M. X., Barroso, R. M., \& Flores, Roberto M. V. Diagnóstico da cadeia produtiva da piscicultura no Estado de Tocantins. Embrapa Pesca e Aquicultura-Boletim de Pesquisa e Desenvolvimento (INFOTECA-E), 2014.

Santos, M. P. N., Seixas S., Aggio R. B. M., Hanazaki N., Costa M., Schiavetti A., Dias J. A., \& Azeiteiro U. M. A. Pesca enquanto Atividade Humana: Pesca Artesanal e Sustentabilidade. Revista de Gestão Costeira Integrada, 12(4), 405-427.

Silva, A. S. S. et al. Caracterização da pesca artesanal em munícipios da baixada maranhense - Brasil. Enciclopédia Biosfera, nº 23, ano:2016.

Valenti, W. C., Pereira, J. A., \& Borghetti, J. R. (2000) Aquicultura no Brasil: bases para um desenvolvimento sustentável. Brasília, DF: CNPq, Ministério da Ciência e Tecnologia. 399p.

Vidal, M. F. Panorama da piscicultura no Nordeste. Caderno Setorial ETENE.

Zacardi, D. M. et al. (2017) Caracterização socioeconômica e produtiva da aquicultura desenvolvida em Santarém, Pará. Acta of Fisheries and Aquatic Resources, 5(3), 102-112. 